\title{
CFD Simulation of Air Flow Behaviour at Different Flow Rates in a Turkish Woodwind Instrument (Turkish Treble Recorder)
}

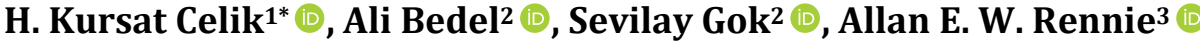 \\ ${ }^{1}$ Department of Agricultural Machinery and Technology Engineering, Akdeniz University, Antalya, Turkey \\ ${ }^{2}$ Turkish Folk Music Department, Antalya State Conservatory, Akdeniz University, Antalya, Turkey \\ ${ }^{3}$ Engineering Department, Lancaster University, Lancaster, UK \\ Email: `hkcelik@akdeniz.edu.tr, alibedel@akdeniz.edu.tr, sevilaygok@akdeniz.edu.tr, a.rennie@lancaster.ac.uk
}

How to cite this paper: Celik, H.K., Bedel, A., Gok, S. and Rennie, A.E.W. (2021) CFD Simulation of Air Flow Behaviour at Different Flow Rates in a Turkish Woodwind Instrument (Turkish Treble Recorder). Open Journal of Acoustics, 11, 1-16.

https://doi.org/10.4236/oja.2021.111001

Received: January 6, 2021

Accepted: March 25, 2021

Published: March 28, 2021

Copyright (c) 2021 by author(s) and Scientific Research Publishing Inc. This work is licensed under the Creative Commons Attribution-NonCommercial International License (CC BY-NC 4.0). http://creativecommons.org/licenses/by-nc/4.0/

\begin{abstract}
In musical instruments, the geometric design and material features of the instrument are the most important factors that determine the sound characteristics of the instrument. Traditional replication and experiment-based handcrafting methods are predominant in the production of Turkish Folk Music wind instruments. The instrument manufacturing and standardization approaches, which include the relevant rules of physics and engineering practices, are limited purely to prototype studies for scientific research purposes. It is almost impossible to find studies on Turkish Folk Music wind instrument design and production involving computer aided design and engineering applications. In this study, an example Turkish woodwind instrument, the Turkish Treble Recorder (dilli kaval) is considered, and the air flow behaviour and acoustic (sound) power magnitudes that occur at different air flow rates are simulated in a computer environment using a Computational Fluid Dynamics (CFD) simulation technique. In the study, numerical and visual outputs related to air behaviour at different air flow rates that may be used in the instrument manufacturing phases were obtained. Acoustic power level was also measured experimentally. Simulation outputs (the acoustic power level) were compared to experimental results in order to validate the simulation results. The comparison revealed that the highest relative difference was calculated as $13.32(\%)$. This value indicated that the simulation results were reasonably consistent with the results of the experimental measurement. Additionally, this study was constructed as a case study that may provide reference for future research studies in this field.
\end{abstract}

\section{Keywords}

Woodwind Instrument, Turkish Treble Recorder (Dilli Kaval), Computation 
Fluid Dynamics, Acoustic, Instrument Design and Manufacturing

\section{Introduction}

The Turkish Treble Recorder (Dilli Kaval), can be defined as a wind instrument which takes the shape of a hollow tube with holes on it. There is evidence that similar wind instruments of this type can be traced to the very early phases of human history. The archaeological findings of Prof. Nicholas J. Conard (The University of Tübingen, Germany) of a cave in Ahv Valley in 2008, reveal that the $21.8 \mathrm{~cm}$ flute made up of the forearm bone of a griffon vulture is the oldest instrument known so far. Using Radio Carbon analysis, it is known that this instrument dates back to earlier than 35,000 B.C. [1]. In addition to Europe, in Asia, the "Sumerian Flute" which is believed was used as early as 5000 B.C., is another sample which was found in a Sumerian grave dating back to 2800 B.C. during excavations conducted by a committee from Pennsylvania University and the British Museum [2]. It is very difficult to give precise statements about the origin of the flute/recorder or reedpipe; however, archaeological findings show that reedpipes have been used for a very long time. Although these instruments are termed flutes "in the cultural and musical systems of the nations in terms of their structural features", it is seen that morphologically similar instruments are referred to by various names in different geographical region. The reedpipe is referred to as "flute" in Ancient Egypt, "Auloş" in Assyrian-Phenicia-LydianHebrew-Syria and Ancient Greece, and "Nâ" by Sumerians [3]. It is assumed that Kaval, the Turkish term for reedpipe, is derived from the word "kav" which means empty and hollow in Turkish [4]. This term is similar to the word "oyuk, ovuk, kovuk, and kavuk" which all mean "hole in the tree trunk". In Anatolian geography, it is also possible to hear the word "Kaval" as "kuval, guval, gaval, or gavel" due to the various dialects of Turkish [5].

The Turkish Treble Recorder can be defined as a wind instrument which is in the shape of a hollow tube. Reedpipes are valid in various types, $25-80 \mathrm{~cm}$ in length, provided that they have $5-7$ holes on the front and a thumb hole in the back. Trees such as plum, apricot and juniper are generally preferred in the production of reedpipes. It is possible to classify the Treble Recorder into two types: as duct and end-blown in terms of blowing function. Sound is obtained by blowing directly into a tongue (duct) structure (labium) that serves to make sound at the tip. The end-blown kaval, on the other hand, does not have any tongue (duct) structure that allows it to make a sound with both ends and it is sounded with the ability of the performer to blow at a certain angle position. In addition, it is possible to say that both types of reedpipes have diatonic and chromatic curtain structures in various regions within the framework of the musical structure characteristics of the region. Turkish Treble Recorder has features that provide a wide sound field by obtaining 8,5 and 4 accretions from its curtains according to the blowing intensity. Therefore, the intensity of the air 
being blown by a musician, plays an important role in the performance of the instrument.

When examining the instruments used in present Anatolia, it is seen that there is a limited number of studies on the sound formation, sound characteristics and instrument manufacturing techniques of the instruments. This situation is also true for the Turkish Treble Recorder, which is one of the Turkish Folk Music woodwind instruments. Nowadays, the production of the Turkish Treble Recorder is undertaken with traditional sampling, using trial and error methods of producers from the past to the present in addition to the efforts of professional local performers. However, the personal performance differences that emerged with the extensive use of woodwind instruments in professional performance and education over time, lead to the structural diversity of the instrument. Therefore, as in all instruments, in order to ensure unity in the field of professional performance and education, it is necessary to understand the sound formation processes of the woodwind instruments under certain scientific foundations and methods and to make standard production methods applicable.

Considering international literature, shows us that research on the physical sound production mechanisms of wind instruments was first examined by Helmholtz (1885) and Rayleigh (1894) [6]. Fundamentally, Helmholtz (1885) explained the movement of air flow generated within the instrument (jet flow: air flow created by spraying fluid from a certain geometry) in terms of the convection of the musical instrument with the acoustic flow at the inlet of the resonator [7]. Rayleigh (1894), on the other hand, revealed that the jet flow has an unstable structure that can increase the acoustic field formed in a reedpipe geometry [8]. These two studies have contributed scientifically in terms of defining the intra-instrument air flow that occurs in wind musical instruments and explains other phenomena related to sound physics theoretically. Subsequent studies have greatly expanded the phenomenon of sound formation in wind instruments with research based on experimental methods [9]-[26].

McIntyre et al. (1983) emerge as the pioneer of the first simulation studies on sound generation in wind instruments [27]. Recently, international studies in this field using advanced computers and numerical method-based engineering simulations contribute to this research area [28]-[35]. These literatures also provide a good understanding of numerical solutions of the compressible Navier-Stokes equations in various aspects of sound production in recorder like musical instruments.

Considering such studies today, it can be concluded that the number of scientific studies in which sound physics and the new generation of computer aided engineering applications actively applied in the production of such instruments are limited internationally, and that, unfortunately such studies are almost non-existent in Turkey. In the field of Turkish Folk Music, there is no previous research involving Computational Fluid Dynamics (CFD) simulation that aids in the optimised production of woodwind instruments.

In this study, the aim is to simulate the behaviour of air flow in an example 
Turkish Treble Recorder and to understand how the air flow changes in frequency and acoustic power magnitudes at different breath (jet flow) rates. In the study, the behaviour of air flow occurring at different breath rates in the Turkish Treble Recorder was simulated by means of the CFD techniques. As a result, useful numerical and visual outputs were obtained that may be used in the design and manufacture of the geometric structure of such music instruments.

\section{Material and Method}

\subsection{Acoustic and CFD}

The primary goal of Musical Instrument Physics Research, in order to contribute to the scientific understanding of the field, is to design precise models that are very close to the acoustic properties of traditionally produced instruments. In this context, when the flute and flute-like wind instruments are considered, the flow in the instrument mouthpiece becomes more complicated with the separation of the flow in the instrument duct (labium). This causes the scattering of the vortexes formed in the flow channel in the air flow and the change of the jet flow structure from laminar to turbulent flow. The unstable flow formed here, creates an acoustic value. Based on the work of Lighthill (1952), Proudman (1952) derived analytical expressions to approximate sound intensity resulting from isotropic turbulent flow occurring at low Mach numbers in terms of kinetic energy and propagation rate of flow turbulence [36] [37]. The major advantage of this approach is that the flow-induced acoustic value for the steady-state condition can be estimated from the resolved CFD calculation data [38].

Proudman's approach gives the acoustic power depending on the unit volume of isotropic turbulence in terms of $\mathrm{W} \cdot \mathrm{m}^{-3}$.

$$
P_{a}=\alpha \rho_{0}\left(\frac{u^{3}}{l}\right) \frac{u^{5}}{\alpha_{0}^{5}}
$$

In Equation (1), $u$ and $l$ are the turbulent velocity and length scale. Also, $\alpha_{0}$ is the sound speed and this value is defined as a pattern constant. Equation (1) can be rewritten in terms of turbulent energy $(k)$ and turbulent dissipation $(\varepsilon)$ as follows:

$$
P_{a}=\alpha_{\varepsilon} \rho_{0} \varepsilon M_{t}^{5}
$$

Here;

$$
M_{t}=\frac{\sqrt{2 k}}{\alpha_{0}}
$$

The rescaled $a_{0}$ constant is considered as 0.1 in the CFD software based on the calibration of Sarkar and Hussaini (1993) [39]. So, the acoustic power value calculated from Equation (4) can also be expressed in decibel (dB).

$$
L_{p}=10 \log \left(\frac{P_{a}}{P_{r e f}}\right)
$$

In Equation (4), $P_{\text {ref }}$ is the reference acoustic power and it is accepted as 
$1.00 \mathrm{e}-12\left(\mathrm{~W} \cdot \mathrm{m}^{-3}\right)$.

CFD is a numerical method used to analyse the flow and thermal behaviour of a fluid in engineering applications. The history of CFD started in the early 1970's. Around that time, it became an acronym for a combination of physics, numerical mathematics, and, to some extent, computer sciences employed to simulate fluid flows [40]. The main purpose of CFD-based flow simulations is to understand the physical events that occur during the flow of defined fluid around and in the internal fluid regions of the geometry/objects [41]. Advanced computing technologies, aid us successfully and widely in many different engineering applications. The solution of Navier-Stokes equations is the basic process in order to simulate a three-dimensional (3D) flow behaviour in a CFD analysis. In this process, the following factors are included: fluid mass, momentum and physics laws regarding energy conservation used in fluid behaviour calculations. The fluid simulation process is performed by following a certain basic application algorithm in the software [42]. The application algorithm is given in Figure 1.

\subsection{CFD Geometry}

Flow behaviour in CFD simulations is directly related to the geometry of the objects under consideration and realistic geometric modelling plays an important role in obtaining realistic simulation results. For this reason, the 3D model of the woodwind instrument discussed in this study, considering the original dimensions, was created in SolidWorks 3D parametric solid modelling software by means of a reverse engineering approach. In this study, a Turkish Treble Recorder $\left(\mathrm{F}^{*}\right)$ with a total of eight holes and a length of $305 \mathrm{~mm}$ and an average inner hole diameter of $11.5 \mathrm{~mm}$ was used. Verge (1995) suggests a certain ratio between dimensions in the measurement of jet opening and duct geometries in wind instruments such as the flute [6]. This ratio is defined as approximately 4 . However, the basic measurements may vary since the geometric dimensions of the fipple and the mouthpiece (jet opening), where the sound is produced, may

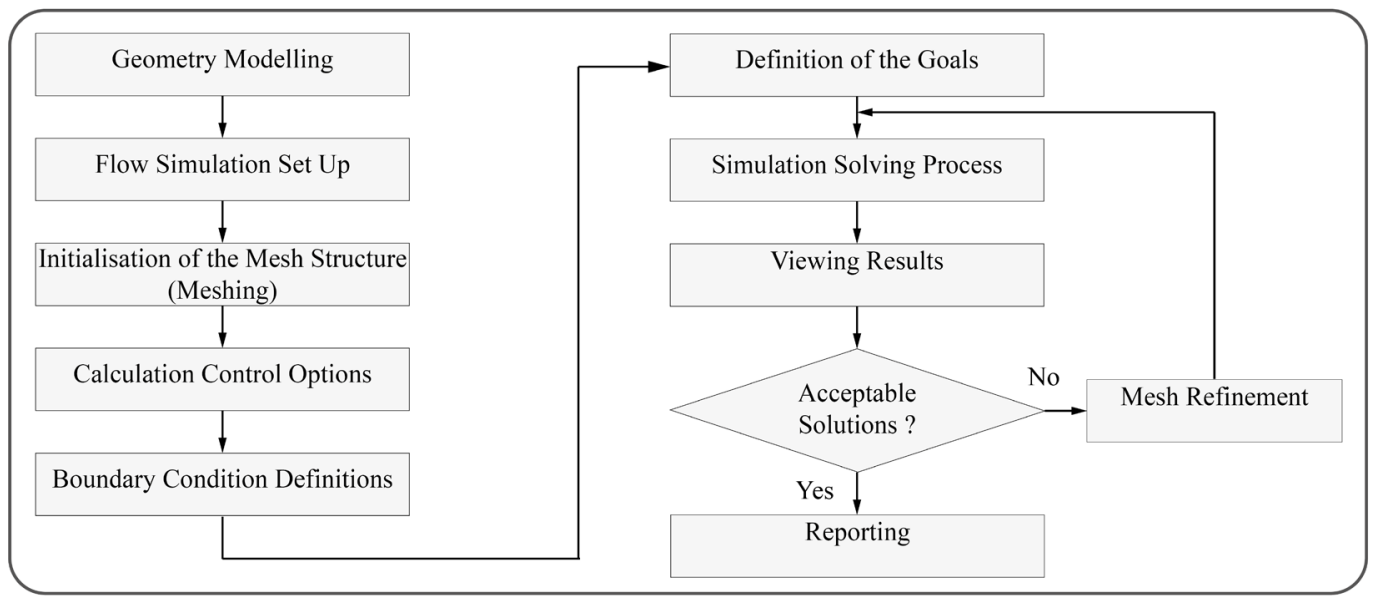

Figure 1. CFD Application algorithm (flowchart). 
not have a certain standard in the production of the traditional Turkish Folk Music woodwind instruments. In the example Turkish Treble Recorder geometry, the distance between the jet opening and duct was $6 \mathrm{~mm}$, the jet inlet and outlet height was $1.7 \mathrm{~mm}$ and $0.85 \mathrm{~mm}$, respectively, and the tongue angle was $12.5^{\circ}$. Images of the Turkish Treble Recorder discussed in the study and its 3D solid model details are given in Figure 2.

\subsection{CFD Analysis}

Although numerical method-based simulation studies integrated with modern computer and related software technologies can provide satisfactory approximate solutions in modelling physical realities, modelling and simulating physical phenomena addressed in nature and in controlled environments in accordance with physical realities contains some difficulties. Some of these limiting challenges can be listed as: material, fluid, dynamic environmental factors and the like, which cannot be predicted and encountered in the analysis setup stage. For this reason, analysis setups are determined within the framework of some mandatory assumptions for this type of numerical method based simulation study. Accordingly, in the Turkish Treble Recorder analysis setup discussed in this study, the first four tones from the head of the recorder were assumed in closed playing position (D0, D1, D2 and D3 tone holes were closed) and four different breath speeds (air intake rates) $\left(2 \mathrm{~m} \cdot \mathrm{s}^{-1}, 4 \mathrm{~m} \cdot \mathrm{s}^{-1}, 5.5 \mathrm{~m} \cdot \mathrm{s}^{-1}\right.$ and $10 \mathrm{~m} \cdot \mathrm{s}^{-1}$ ) were taken at this position; thus, the air flow behaviour was investigated for this recorder model. SolidWorks Flow Simulation (CFD simulation) software was utilised in order to simulate the air flow behaviour in and around the recorder

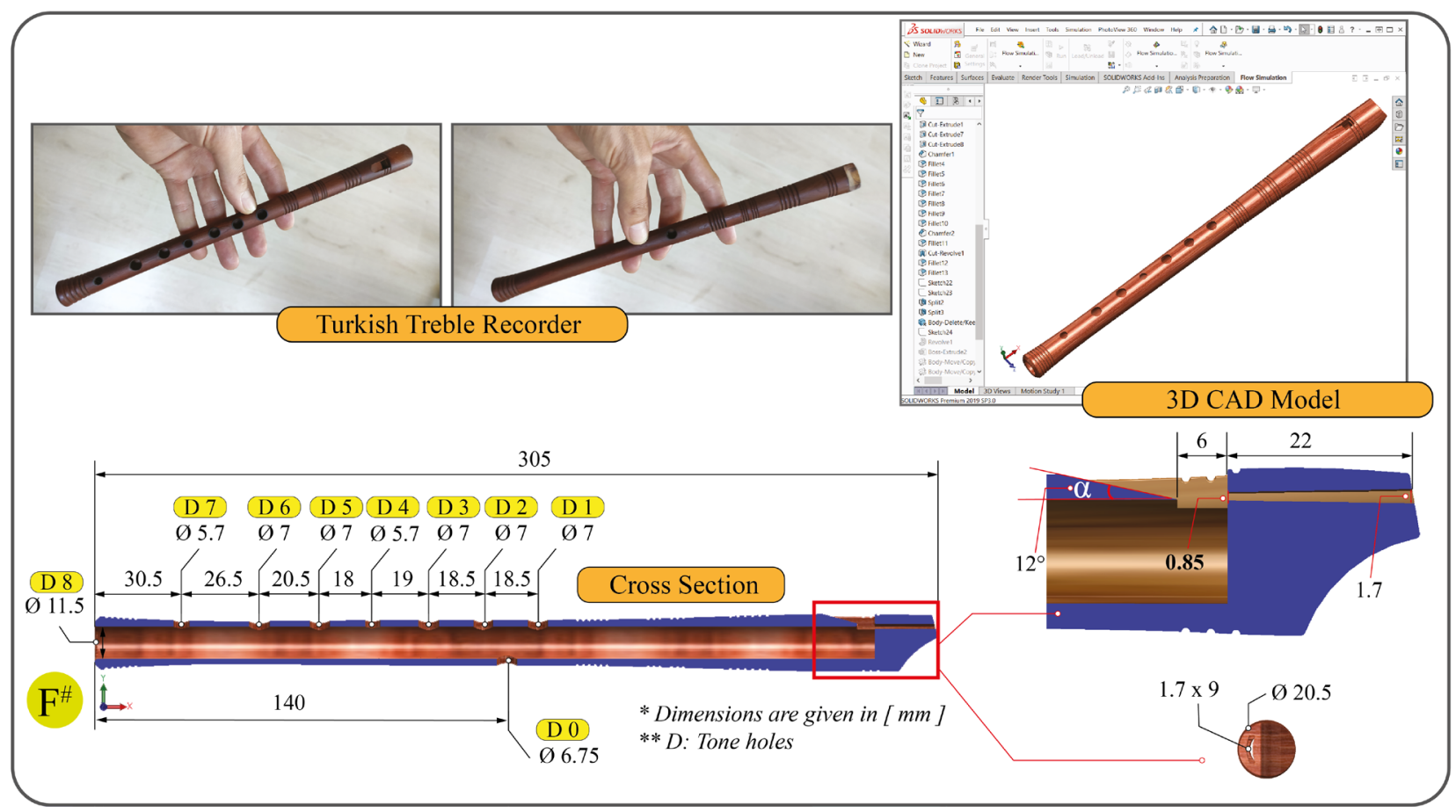

Figure 2. Images of the Turkish Treble Recorder and the 3D solid model details. 
discussed in the study. Breath rates were measured experimentally with reference to four different note values with four different frequency values using an adjustable air compressor and anemometer; these were defined as the input parameters in the simulation. Each measurement was carried out in triplicate during the trials. In addition, acoustic (sound) power levels at these four different frequencies values were also measured using a mobile sound level meter (decibel meter). Acoustic power level measurements were recorded with a sampling rate of $5 \mathrm{~Hz}$ over a duration of $10 \mathrm{~s}$, and average acoustic power level values were calculated for each frequency value. Air was defined as the fluid. Identical boundary conditions are defined for each analysis setup; the recorder model is assumed to be a rigid geometry, and the surface roughness is accepted as $2 \mu \mathrm{m}$. In the analyses, a gravitational constant $\left(9.81 \mathrm{~m} \cdot \mathrm{s}^{-1}\right)$ was taken into consideration and it was assumed that the recorder was played at ambient temperature $\left(20^{\circ} \mathrm{C}\right)$ under $1 \mathrm{~atm}(101,325 \mathrm{~Pa})$ ambient pressure. In all analyses, the original geometry of the solid model has been preserved and the ornamental channels located in the outer geometry of the recorder were included in the analysis in order to observe the air flow in the outer region of the recorder. The simulation technology utilised in this study is based upon the use of cartesian-based meshes and meshing technology is one of the key elements of the CAD/CFD bridge for CAD-embedded CFD. As a result of using cartesian-based meshes, the model have cells which are located fully in solid bodies (solid cells), in the fluid (fluid cells) and cells intersected the immersed boundary (which is termed "partial cells") [43]. In the CFD model, the cell separation process (meshing) was performed to model the flow behaviour with satisfactory accuracy by considering the number of cells in the software and the solution time optimisation. Analyses were performed at the domain of the fluid computing volume of $340 \mathrm{~mm} \times 60$ $\mathrm{mm} \times 60 \mathrm{~mm}$. In many flow analyses, defining the parameters related to turbulent flow is a complex process. The simulation software utilised in this study employs transport equations for the turbulent kinetic energy and its dissipation rate, using the $k$ - $\mathcal{E}$ model [43]. The modified $k$ - $\varepsilon$ turbulence model with damping functions proposed by Lam and Bremhorst (1981) describes laminar, turbulent, and transitional flows of homogeneous fluids [44]. In this context, the parameters related to linear and turbulent flow are defined as automatic values that are suggested in the simulation software and calculated according to geometry and fluid type (Turbulent Energy $(k)=1 \mathrm{j} \cdot \mathrm{kg}^{-1}$; Turbulent Dissipation $(\varepsilon)=1$ $\left.\mathrm{W} \cdot \mathrm{kg}^{-1}\right)$ [42]. Boundary conditions, cell structure, numerical data collection lines and experimental measurement results defined in the analysis setup are shown in Figure 3.

\section{Results and Discussion}

After the completion of analysis setup phase, all analyses were solved. Visual and numerical results were obtained. The simulation results visually demonstrated the air flow behaviour in and around the recorder at different breath rates. In 


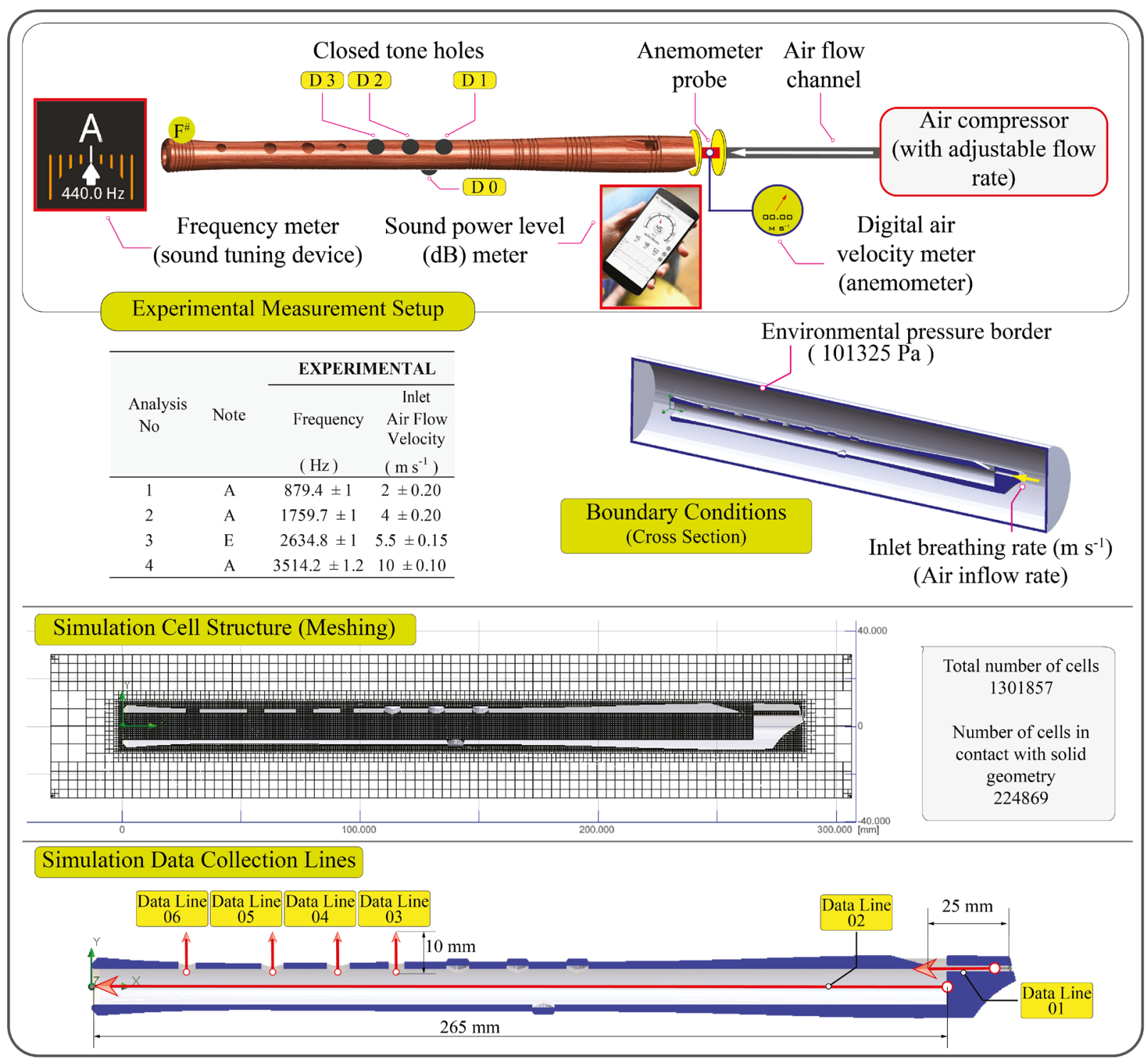

Figure 3. Boundary conditions defined in the analysis setup, cell structure, data collection lines and experimental measurement details.

this flow behaviour, the highest air velocity, pressure and acoustic (sound) power level regions inside the kaval, and numerical values in these regions, were obtained. In addition, data collection lines were created to reveal the air flow velocity and pressure changes inside the ducted tube and the open tone holes in the handle area (Figure 3 ) and the change in these lines was graphically expressed. Visual and graphical outputs showing simulation results are given in Figures 4-7, and numerical data and graphical expressions of experimental measurement and simulation outputs are given in Figure 8.

Examining the numerical results of the simulation indicates that with the increase in the inlet breath rate, an increase occurs in the values of the inner recorder velocity, pressure and acoustic power level (Figure 8). Noting these values, the increase inside the recorder air velocity and pressure define an almost 


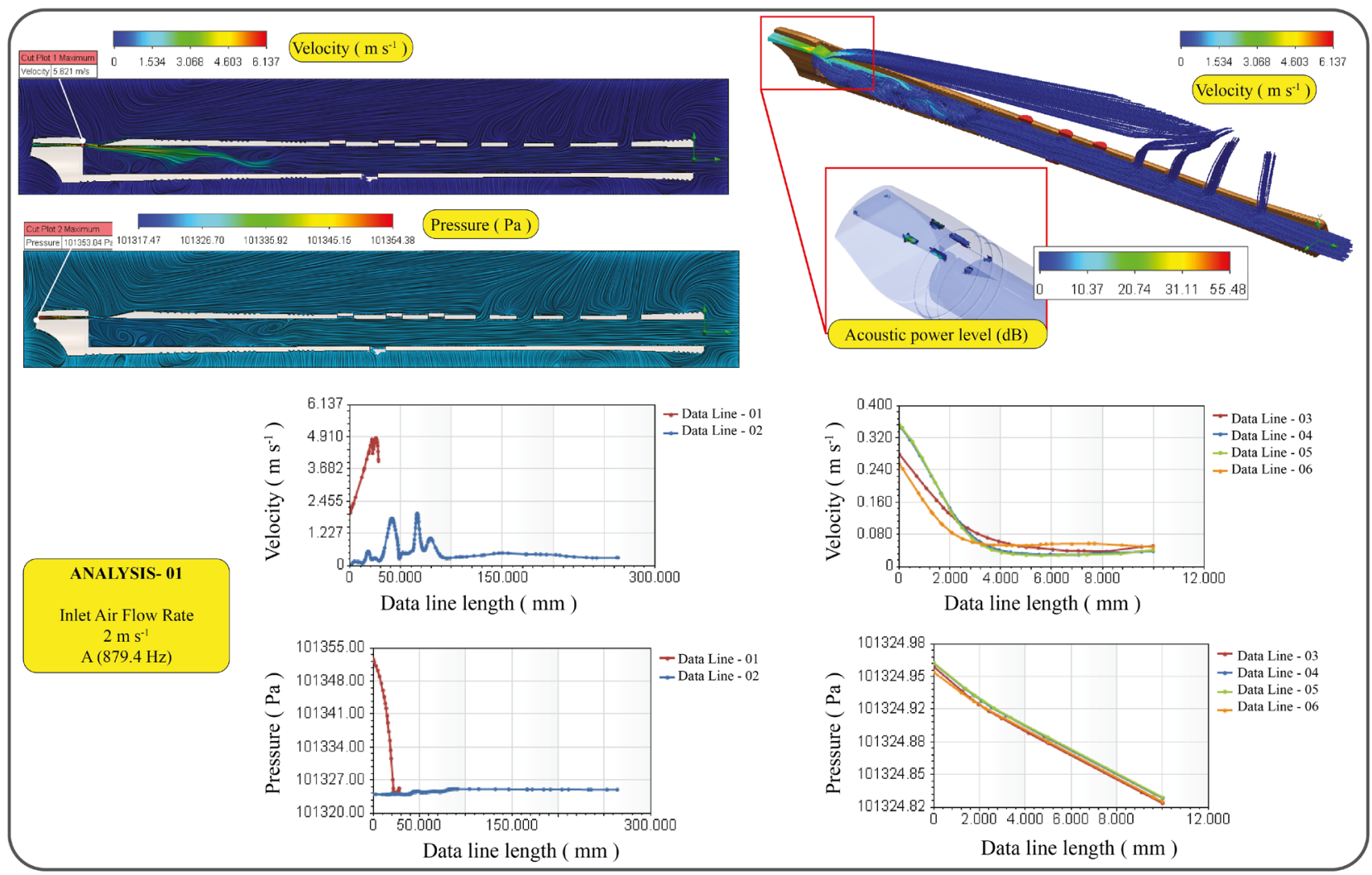

Figure 4. Simulation outputs of Analysis 1.

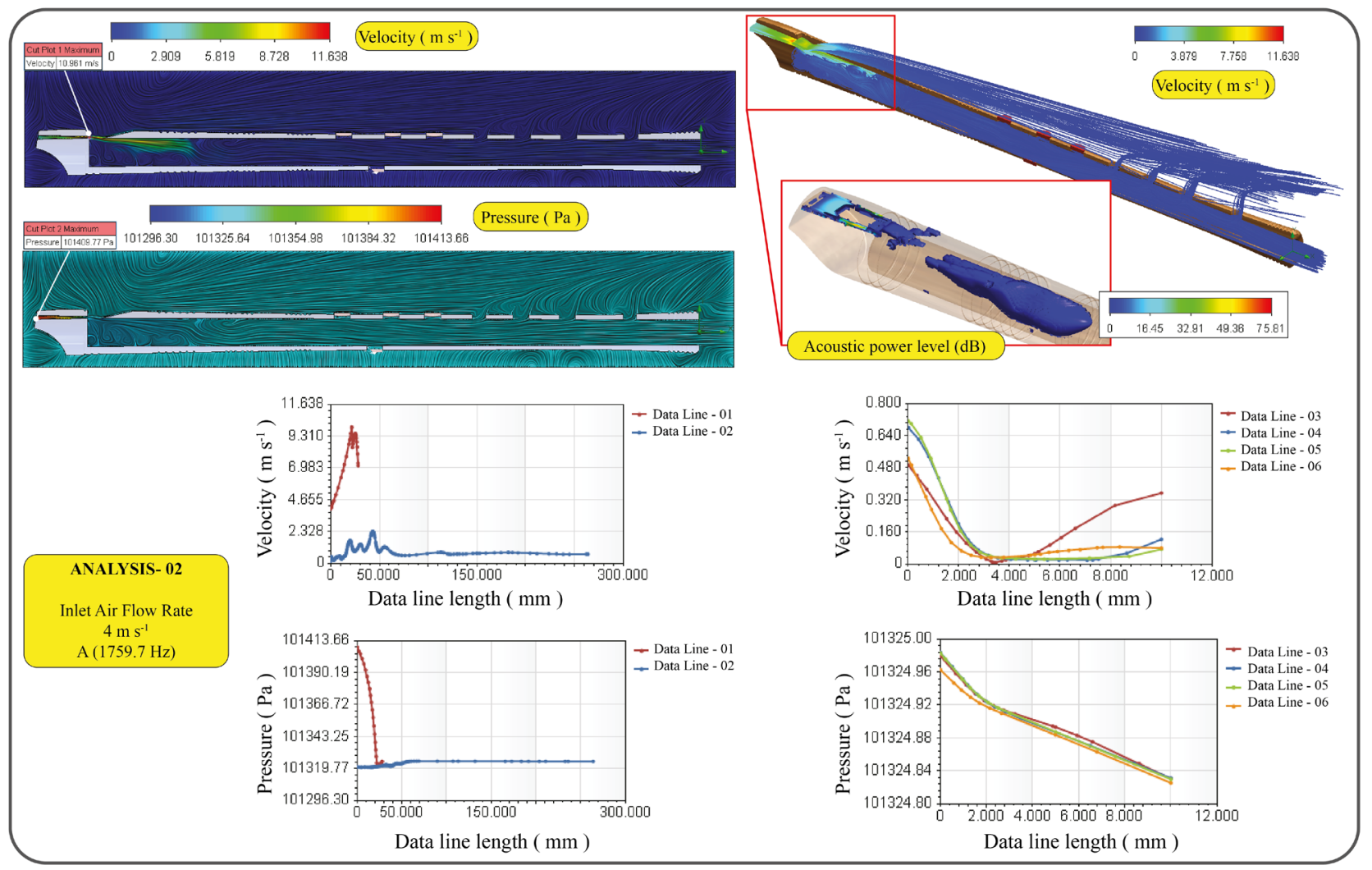

Figure 5. Simulation outputs of Analysis 2. 


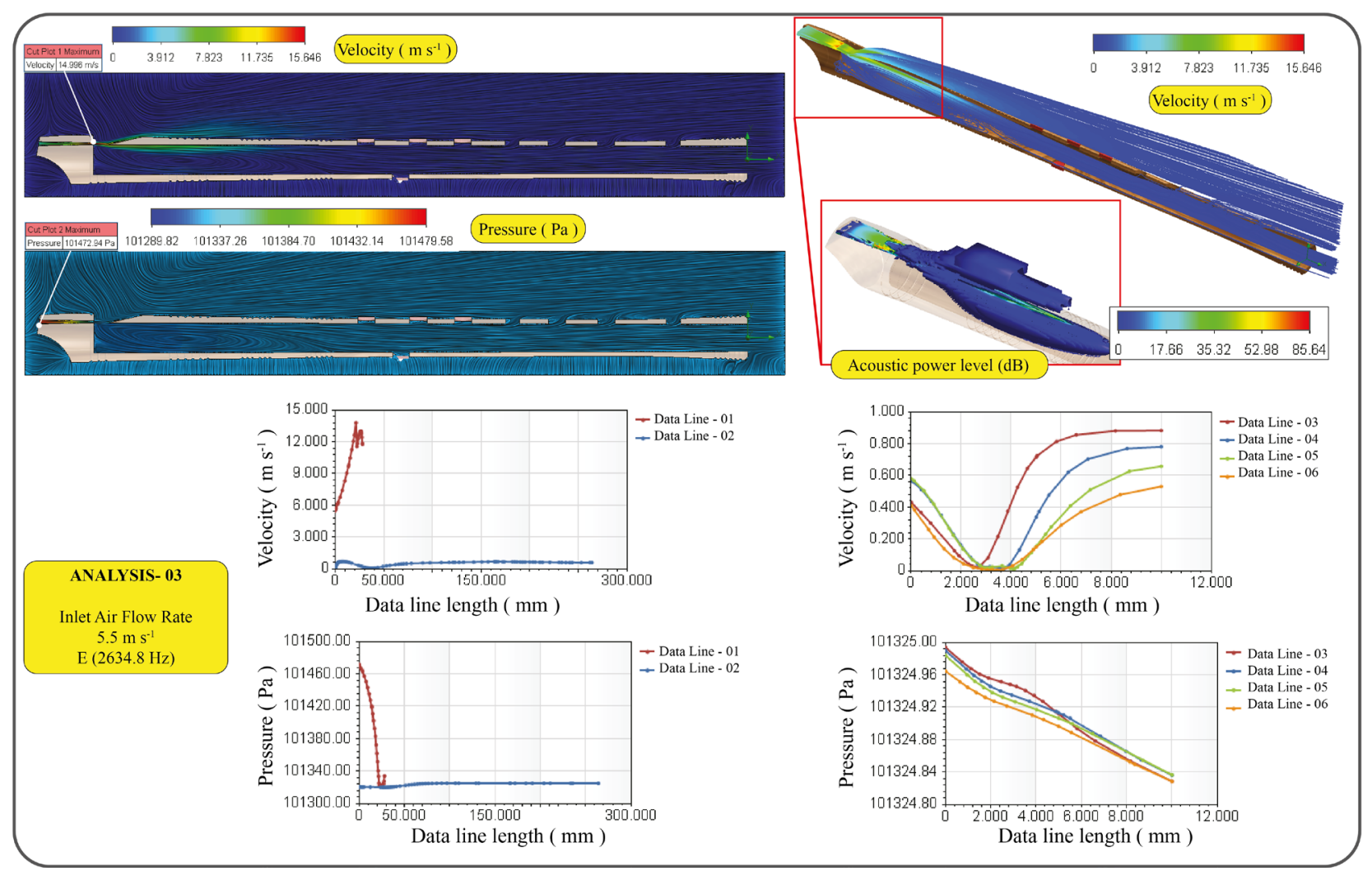

Figure 6. Simulation outputs of Analysis 3.
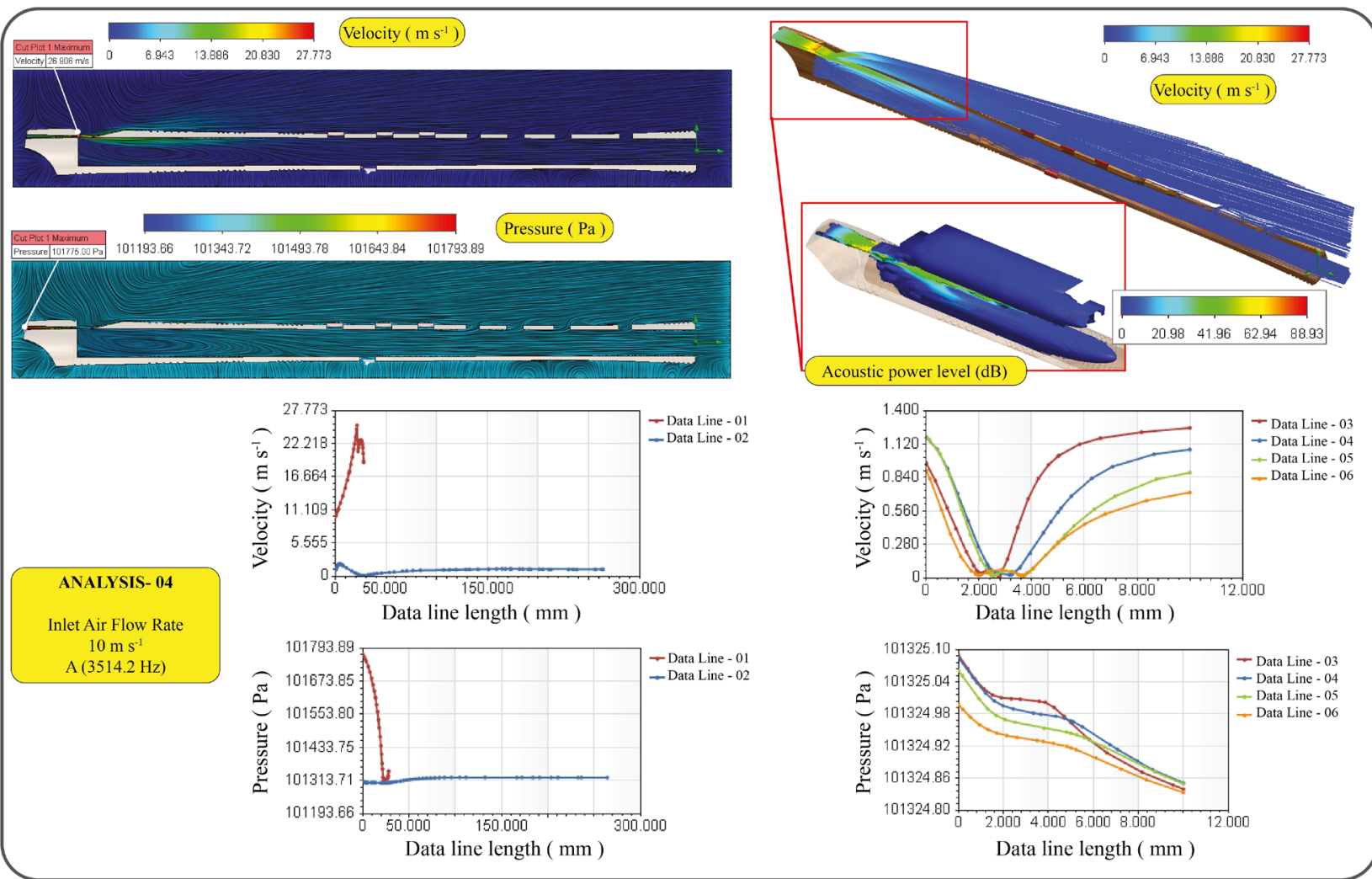

Figure 7. Simulation outputs of Analysis 4. 


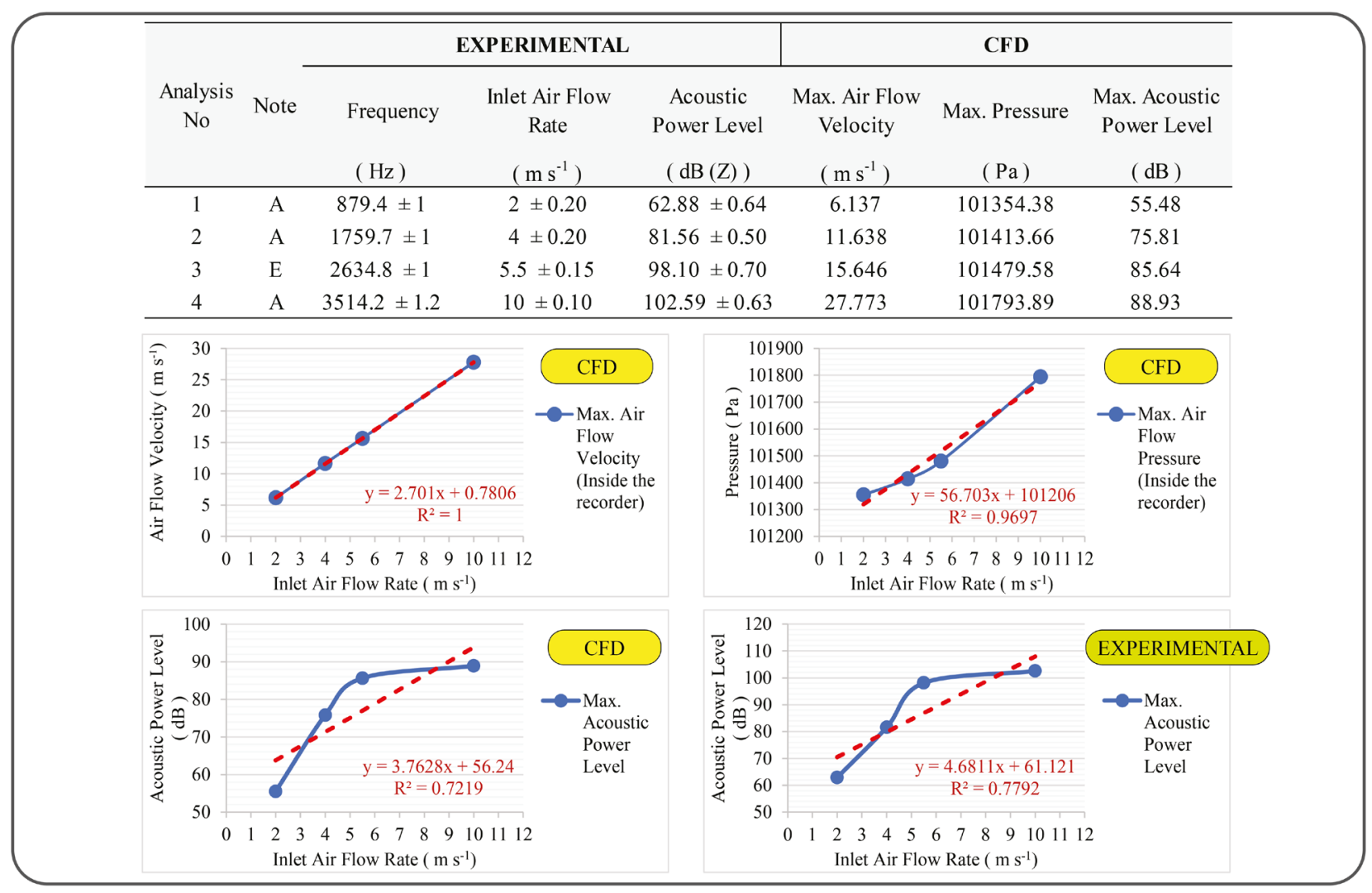

Figure 8. Numerical data and graphical expressions of experimental measurement and simulation outputs.

completely linear streamline with the increase in inlet breath rate, while the acoustic power level shows a nonlinear difference at the highest inlet air velocity. The maximum flow velocity value in a recorder's duct region was found to be $27.773 \mathrm{~m} \cdot \mathrm{s}^{-1}$ and the highest inlet air velocity value was $10 \mathrm{~m} \cdot \mathrm{s}^{-1}$. Also, the highest acoustic (sound) power level at this inlet air speed was calculated as $88.93 \mathrm{~dB}$. However, for cross-section fluid behaviour, in Analyses 1 and $2\left(V=2 \mathrm{~m} \cdot \mathrm{s}^{-1}\right.$ and $V=4 \mathrm{~m} \cdot \mathrm{s}^{-1}$ ), air vortexes that support sound formation are seen in smaller diameter and more than one in number, under the jet opening. It has been observed in Analyses 3 and $4\left(V=5.5 \mathrm{~m} \cdot \mathrm{s}^{-1}\right.$ and $\left.V=10 \mathrm{~m} \cdot \mathrm{s}^{-1}\right)$ that these vortexes are larger and singular. This situation reveals how sound formations at different frequencies change with air movement in terms of acoustics. Fluid motion has a direct relationship with the geometry in which it flows. As the flow vortex behaviour and sound formation will change depending on this geometry, the exact sizing of these geometries will play a critical role in the standardisation efforts of this type of wind instrument. Another issue is the material from which the instrument is made. Based on experience, it is understood that the material texture of the wood used in such wood-structured wind instruments is effective on sound formation. Since the recorder geometry discussed in this study is considered to be rigid, the effect of material texture on the change of acoustic power level is not included in these analyses. However, this situation can be addressed in further studies. 


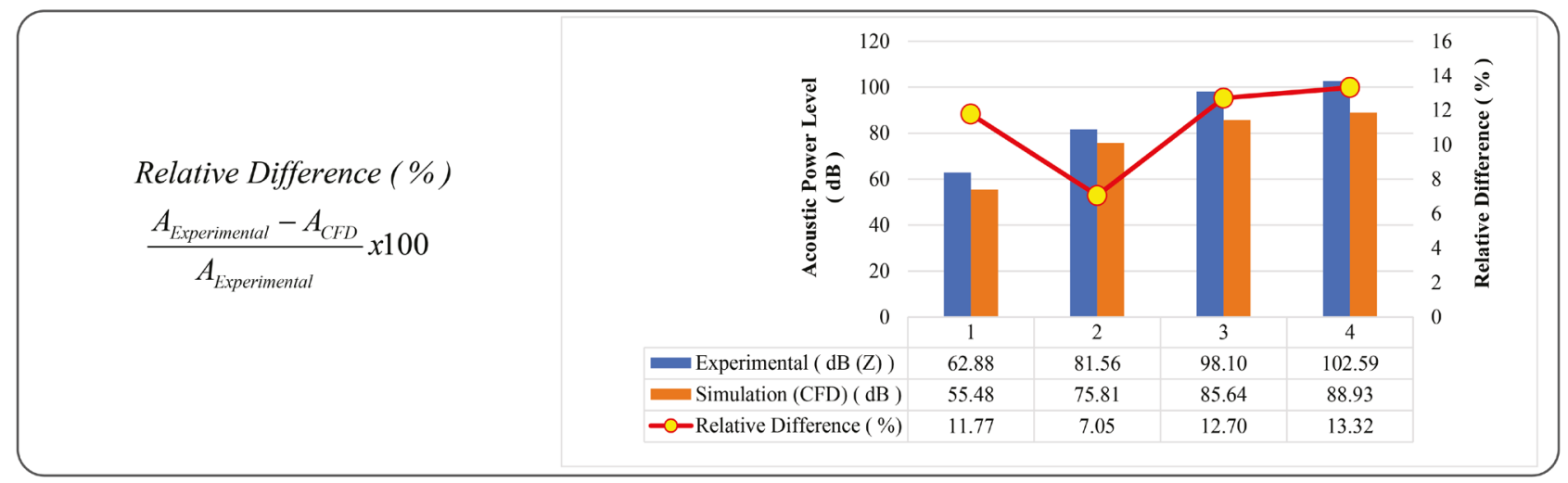

Figure 9. The comparison of experimental measurement and simulation results.

CFD simulation technique is very useful in revealing the air flow behaviour in this type of fluid analysis, however, it should be highlighted that this type of numerical method-based simulation study only provides approximate solutions to real-life physical events. For this reason, the extent to which the results obtained in simulation studies reflecting real physical conditions should be carefully evaluated. At such, the most appropriate method in validating simulation results is to perform experimental validation. In this study, a comparison of simulation and experimental data was carried out through acoustic power (sound) level measurements. Percentage relative differences of the simulation results were calculated with reference to the experimental data. As a result, the relative difference varied between $7.05 \%$ and $13.32 \%$ (Figure 9). This indicates that the values obtained from the simulation results are compatible with the experimental measurements to a satisfactory level [45].

For the final evaluation result for the simulation validation study: unexpected and unpredictable dynamic conditions in actual operating conditions, limits in simulating these conditions, a solution approach specific to numerical methods, mandatory assumptions made to eliminate the limits within the framework of this approach, considering the capacity of the simulation solver platform and eliminating any anomaly in the obtained flow behaviour, it was concluded that all CFD analyses set up to simulate the physical conditions defined for the Turkish Treble recorder, were all undertaken correctly and had the ability to represent satisfactorily, the real flow behaviours and could be used in the production of this woodwind instrument.

\section{Conclusion}

Unfortunately, it cannot be said that there is a standardisation in the geometric structure and thus, the manufacture of wind instruments for Turkish Folk Music. When we examine the techniques used by the present instrument manufacturers, we notice that they generally use the measurements that were predetermined by trial and error. This situation leads to the structural diversification of the instrument and creates the risk of losing its original structure from the past 
over time. However, in order to ensure unity in the field of professional performance and education in the use of such instruments, it is necessary to reveal the acoustic formation processes and standard geometric features under certain scientific foundations and methods. Thus, by making standard production methods applicable, it will be possible to carry these instruments to the future and to achieve unity in instrument training. Computer-aided design and manufacturing applications that are developing today have become applicable in studies related to Turkish Folk Music instrument design and manufacturing. However, there are very few such studies in terms of quantity. Therefore, this can be considered among the first examples of such studies in Turkey for a Turkish treble recorder. In this study, an example Turkish treble recorder is considered and useful simulation outputs representing the flow behaviours inside the recorder that occur in sound formation at different frequency values are obtained. These outputs can be used in the production of this type of wind instrument. The simulation outputs were evaluated experimentally, with the maximum difference ratio calculated (13.32\%); thus, it was found that the simulation results were compatible with the experimental measurement results. Moreover, this study is constructed as a case study that will provide reference for further research in this field.

\section{Acknowledgements}

This research is partly supported financially by The Scientific Research Projects Coordination Unit of Akdeniz University (Turkey).

\section{Conflicts of Interest}

The authors declare no conflicts of interest regarding the publication of this paper.

\section{References}

[1] Aytek, A. (2010) İlk Müzik Aleti Flüt (Flute the First Musical Instrument). Bilim ve Tek Derg, 82-84. (In Turkish)

[2] Aydın, A. (2015) Türkiye'de Dilsiz Kaval İçin Yapılmış Metodolojik Çalışmalar Üzerine Bir İnceleme [An Examination on Methodological Works Done for Shepherd's Pipe in Turkey]. Ordu University (Turkey). http://earsiv.odu.edu.tr:8080/xmlui/handle/11489/210

[3] Tarlabasi, B. (1990) Ortaöğretim İçin Kaval Metodu (Kaval Method for Secondary Education). ITÜ Türk Musikisi Devlet Konservatuari, İstanbul.

[4] Gazimihal, M.R. (2001) Türk Nefesli Çalgıları (Türk Ötkü Çalgıları) (Turkish Woodwind Instruments (Turkish Song Instruments). 2nd Edition, Kültür Bakanlığı, Millî Folklor Araştırma Dairesi (Turkey), Ankara.

[5] Yurtcu, C. (2006) Bir performans aracı olarak kaval ve teknik gelişimi (The Kaval and Its Tecnical Development as a Performence Instrument). Istanbul Technical University, Istanbul.

[6] Verge, M.-P. (1995) Aeroacoustics of Confined Jets, with Applications to the Physical Modeling of Recorder-Like Instruments. Technische Universiteit Eindhoven, 
Eindhoven.

[7] Helmholtz, H. (1954) On the Sensations of Tone (Dover Books on Music). 2nd Edition, Dover Publications, Dover.

[8] Rayleigh, J.W.S.B. (1851) The Theory of Sound. The London, Edinburgh, and Dublin Philosophical Magazine and Journal of Science, 2, 162-163.

https://www.tandfonline.com/doi/abs/10.1080/14786445108646853 https://doi.org/10.1080/14786445108646853

[9] Bouasse, H. (1929) Instruments a Vent (Tomes I \& II). Librairie Delagrave, Paris.

[10] Powell, A. (1953) On Edge Tones and Associated Phenomena. Acta Acust united with Acust, 3, 233-243.

[11] Powell, A. (1961) On the Edgetone. The Journal of the Acoustical Society of America, 33, 395. http://asa.scitation.org/doi/10.1121/1.1908677

https://doi.org/10.1121/1.1908677

[12] Cremer, L.V. and Ising, H. (1967) Die selbsterregten Schwingungen von Orgelpfeifen. ACUSTICA, 19, 143-153.

https://jglobal.jst.go.jp/en/detail?JGLOBAL ID=201602010771169336

[13] Coltman, J.W. (1968) Sounding Mechanism of the Flute and Organ Pipe. The Journal of the Acoustical Society of America, 44, 983.

http://asa.scitation.org/doi/10.1121/1.1911240

https://doi.org/10.1121/1.1911240

[14] Coltman, J.W. (1973) Mouth Resonance Effects in the Flute. The Journal of the Acoustical Society of America, 54, 417.

http://asa.scitation.org/doi/10.1121/1.1913593

https://doi.org/10.1121/1.1913593

[15] Coltman, J.W. (1976) Jet Drive Mechanisms in Edge Tones and Organ Pipes. The Journal of the Acoustical Society of America, 60, 725.

http://asa.scitation.org/doi/10.1121/1.381120

https://doi.org/10.1121/1.381120

[16] Elder, S.A. (1973) On the Mechanism of Sound Production in Organ Pipes. The Journal of the Acoustical Society of America, 54, 1554.

http://asa.scitation.org/doi/10.1121/1.1914453

https://doi.org/10.1121/1.1914453

[17] Fletcher, N.H. (1976) Jet-Drive Mechanism in Organ Pipes. The Journal of the Acoustical Society of America, 60, 481.

http://asa.scitation.org/doi/10.1121/1.381105

https://doi.org/10.1121/1.381105

[18] Fletcher, N.H. (1976) Sound Production by Organ Flue Pipes. The Journal of the Acoustical Society of America, 60, 926.

http://asa.scitation.org/doi/10.1121/1.381174 https://doi.org/10.1121/1.381174

[19] Fletcher, N.H. (1976) Transients in the Speech of Organ Flue Pipes-A Theoretical Study. Acustica, 34, 224-233.

https://www.ingentaconnect.com/content/dav/aaua/1976/00000034/00000004/art00 $\underline{007}$

[20] Fletcher, N.H. and Douglas, L.M. (1980) Harmonic Generation in Organ Pipes, Recorders, and Flutes. The Journal of the Acoustical Society of America, 68, 767.

http://asa.scitation.org/doi/10.1121/1.384815

https://doi.org/10.1121/1.384815 
[21] Nolle, A.W. (1983) Flue Organ Pipes: Adjustments Affecting Steady Waveform. The Journal of the Acoustical Society of America, 73, 1821.

http://asa.scitation.org/doi/10.1121/1.389405

https://doi.org/10.1121/1.389405

[22] Castellengo, M. (1976) Contribution à l'étude éxperimentale des tuyaux à bouche [Contribution to the Experimental Study of Blown Pipes]. Université de Pierre et Marie Curie.

http://www.lam.jussieu.fr/Membres/Castellengo/publications/1976a-THESE-Tuyau xFluteOrgue.pdf

[23] Nolle, A.W. (1979) Some Voicing Adjustments of Flue Organ Pipes. The Journal of the Acoustical Society of America, 66, 1612.

http://asa.scitation.org/doi/10.1121/1.383658

https://doi.org/10.1121/1.383658

[24] Nolle, A.W. and Finch, T.L. (1992) Starting Transients of Flue Organ Pipes in Relation to Pressure Rise Time. The Journal of the Acoustical Society of America, 91, 2190. http://asa.scitation.org/doi/10.1121/1.403653 https://doi.org/10.1121/1.403653

[25] Yoshikawa, S. and Saneyoshi, J. (1980) Feedback Excitation Mechanism in Organ Pipes. Journal of the Acoustical Society of Japan (E), 1, 175-191. https://doi.org/10.1250/ast.1.175

[26] Valeriu, I. (1992) Time-Domain Simulation and Linear Analysis of Sound Production in Organ Pipes. Master's Thesis, University of Washington, Washington DC.

[27] McIntyre, M.E., Schumacher, R.T. and Woodhouse, J. (1983) On the Oscillations of Musical Instruments. The Journal of the Acoustical Society of America, 74, 1325. http://asa.scitation.org/doi/10.1121/1.390157 https://doi.org/10.1121/1.390157

[28] Ricardo da Silva, A., Scavone, G.P. and van Walstijn, M. (2007) Numerical Simulations of Fluid-Structure Interactions in Single-Reed Mouthpieces. The Journal of the Acoustical Society of America, 122, 1798.

http://asa.scitation.org/doi/10.1121/1.2759166 https://doi.org/10.1121/1.2759166

[29] Obikane, Y. (2011) Computational Aeroacoustics on a Small Flute Using a Direct Simulation. In: Kuzmin, A., Ed., Computational Fluid Dynamics 2010, Springer, Berlin, Heidelberg, 435-441.

https://link.springer.com/chapter/10.1007/978-3-642-17884-9 54 https://doi.org/10.1007/978-3-642-17884-9 54

[30] Daniel, C. and Petre-Claudiu, C. (2013) Acoustic Characteristics of the Flow over Different Shapes of Nozzle Chevrons. INCAS Bulletin, 5, 53-59. https://doi.org/10.13111/2066-8201.2013.5.3.6

[31] Giordano, N. (2013) Direct Numerical Simulations of the Recorder in Two and Three Dimensions. Proceedings of Meetings on Acoustics, 19, 035062. http://asa.scitation.org/doi/abs/10.1121/1.4798465 https://doi.org/10.1121/1.4798465

[32] Auvray, R., Ernoult, A., Fabre, B. and Lagrée, P.-Y. (2014) Time-Domain Simulation of Flute-Like Instruments: Comparison of Jet-Drive and Discrete-Vortex Models. The Journal of the Acoustical Society of America, 136, 389. http://asa.scitation.org/doi/10.1121/1.4875716 https://doi.org/10.1121/1.4875716

[33] Yokoyama, H., Miki, A., Onitsuka, H. and Iida, A. (2015) Direct Numerical Simula- 
tion of Fluid-Acoustic Interactions in a Recorder with Tone Holes. The Journal of the Acoustical Society of America, 138, 858.

http://asa.scitation.org/doi/10.1121/1.4926902

https://doi.org/10.1121/1.4926902

[34] Miyamoto, M., Ito, Y., Takahashi, K., et al. (2010) Numerical Study on Sound Vibration of an Air-Reed Instrument with Compressible LES.

http://arxiv.org/abs/1005.3413

[35] Onogi, K., Yokoyama, H. and Iida, A. (2019) Analysis of Jet Oscillations with Acoustic Radiation in the Recorder by Direct Aeroacoustic Simulations. The Journal of the Acoustical Society of America, 146, 1427.

http://asa.scitation.org/doi/10.1121/1.5124001

https://doi.org/10.1121/1.5124001

[36] Lighthill, M.J. (1952) On Sound Generated Aerodynamically I. General Theory. Proceedings of the Royal Society of London. Series A, Mathematical and Physical Sciences, 211, 564-587.

https://royalsocietypublishing.org/doi/10.1098/rspa.1952.0060 https://doi.org/10.1098/rspa.1952.0060

[37] Proudman, I. (1952) The Generation of Noise by Isotropic Turbulence. Proceedings of the Royal Society of London. Series A, Mathematical and Physical Sciences, 214, 119-132. https://doi.org/10.1098/rspa.1952.0154

[38] Croaker, P., Skvortsov, A. and Kessissoglou, N. (2011) A Simple Approach to Estimate Flow-Induced Noise from Steady State CFD Data. Aust Acoust Soc 2011, Acoust Break New Gr., 451-458.

[39] Sarkar, S. and Hussaini, M.Y. (1993) Computation of the Sound Generated by Isotropic Turbulence. NASA STI/Recon Tech Rep No. 93-74, 21880. https://dl.acm.org/doi/book/10.5555/869911

[40] Blazek, J. (2015) Computational Fluid Dynamics: Principles and Applications. Third Edition, Elsevier Ltd., New York.

[41] Lomax, H., Pulliam, T., Zingg, D., et al. (2002) Fundamentals of Computational Fluid Dynamics. Applied Mechanics Reviews, 55, B61.

https://asmedigitalcollection.asme.org/appliedmechanicsreviews/article/55/4/B61/4 58325/Fundamentals-of-Computational-Fluid-Dynamics https://doi.org/10.1115/1.1483340

[42] Matsson, J.E. (2019) An Introduction to Solid Works Flow Simulation 2019. SDC Publications, Mission, KS.

[43] Sobachkin, A. and Dumnov, G. (2013) Numerical Basis of CAD-Embedded CFD. NAFEMS World Congress 2013, Salzburg, Austria, June 2013, 1-20.

[44] Lam, C.K.G. and Bremhorst, K. (1981) A Modified form of the k- $\varepsilon$ Model for Predicting Wall Turbulence. Journal of Fluids Engineering, 103, 456-460. https://doi.org/10.1115/1.3240815

[45] Oberkampf, W.L. and Barone, M.F. (2006) Measures of Agreement between Computation and Experiment: Validation Metrics. Journal of Computational Physics, 217, 5-36. https://doi.org/10.1016/j.jcp.2006.03.037 